\title{
THE OTHER WORLD: A FICTIONAL ORBIT
}

\author{
Tim O'Riley \\ Chelsea College of Art \& Design \\ 16 John Islip Street \\ London SW1P 4JU \\ U.K. \\ t.oriley@chelsea.arts.ac.uk
}

\begin{abstract}
Drawing on the familiar material from NASA's lunar explorations and a serendipitous encounter with a memento from the Apollo 11 mission, I am working on an animated film featuring a single, looping orbit around the moon. Rendered from a computer model where planetary positions and orbits are plotted to correspond as far as possible to actuality, the lunar surface itself is based on data collected by the Clementine spacecraft which spent a some months orbiting the moon in 1994. The paper describes and reflects on my work-in-progress on this project in relation to ongoing interests in the philosophies of computing and representation.
\end{abstract}

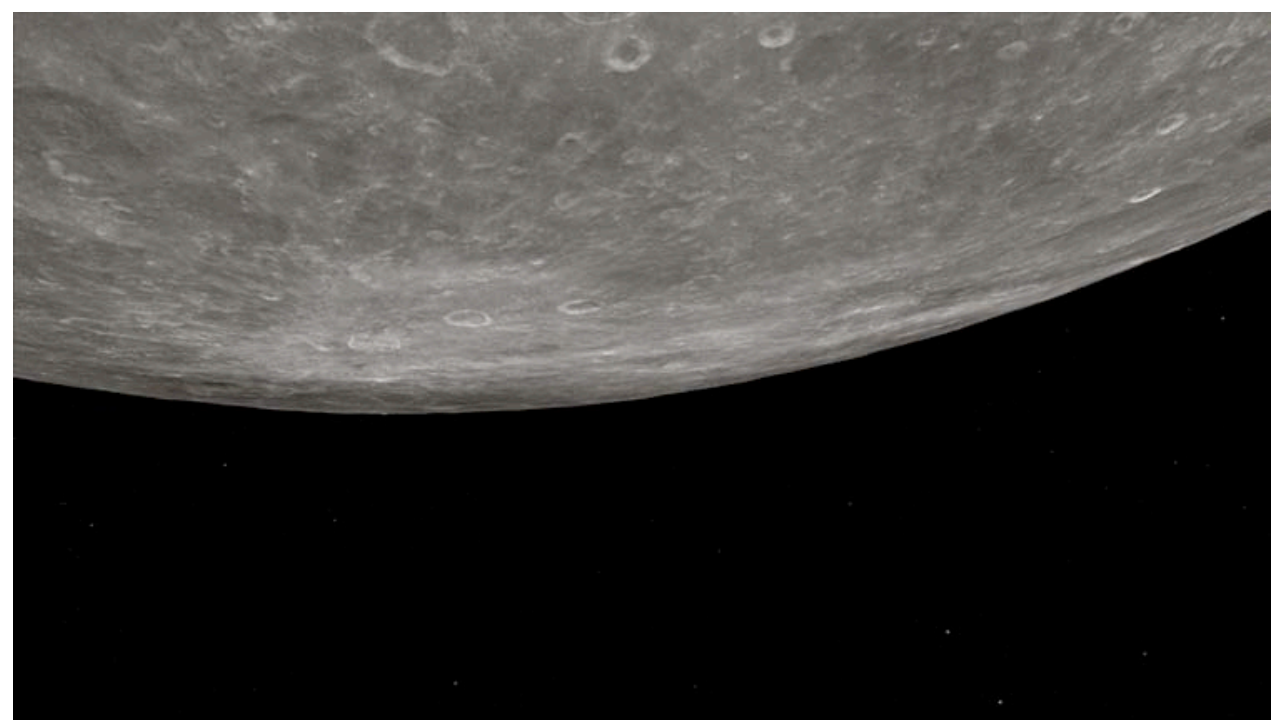

Figure 1

This project emerged out of research and site visits I have made over the past few years to various astronomical observatories in Europe and the USA and relates in part to the Apollo 11 mission in July 1969. During a visit to an observatory outside Dublin a few years ago, I unexpectedly came across a memento from the Apollo 11 mission, namely an Irish flag about the size of a postcard, mounted on a small plaque that, so the plaque's typed label stated, had travelled onboard the famous spacecraft. Led on by a degree of curiosity about the flag and by extension, its possible connection with Apollo 11 command module pilot, Michael Collins (who, it was claimed by some, had Irish connections [1]), I became immersed in the plethora of material relating to lunar science and exploration, its sobering historical and political context [2], as well as related fictional narratives [3] and biographical accounts [4]. 
Trying to build up a sense of this epic journey, like many others I became intrigued by its narratives and representations in a variety of forms (film, photography, sound, text). In particular, Collins' experience was central and in retrospect it seems inevitable, if somewhat speculative, that I should associate him with the flag and its current location. Although Apollo missions 8 and 10 had successfully orbited the moon, Collins was the first person to make this journey alone and for approximately 48 minutes of each two hour orbit, he was entirely cut off from radio contact with mission control and his fellow astronauts on the moon.[5] As he put it, 'I am alone now, truly alone, and absolutely isolated from any known life. I am it... I feel this powerfully - not as fear or loneliness - but as awareness, anticipation, satisfaction, confidence, almost exultation. I like the feeling. Outside my window I can see stars - and that is all. Where I know the moon to be, there is simply a black void; the moon's presence is defined solely by the absence of stars. To compare the sensation with something terrestrial, perhaps being alone in a skiff in the middle of the Pacific Ocean on a pitch-black night would most nearly approximate my situation.'[6] What in many respects was a bold adventure in exploration and science as well as a display of national prestige and power, also struck me as a sublime and existential encounter with the vastness of the cosmos: an embodiment of solitude.

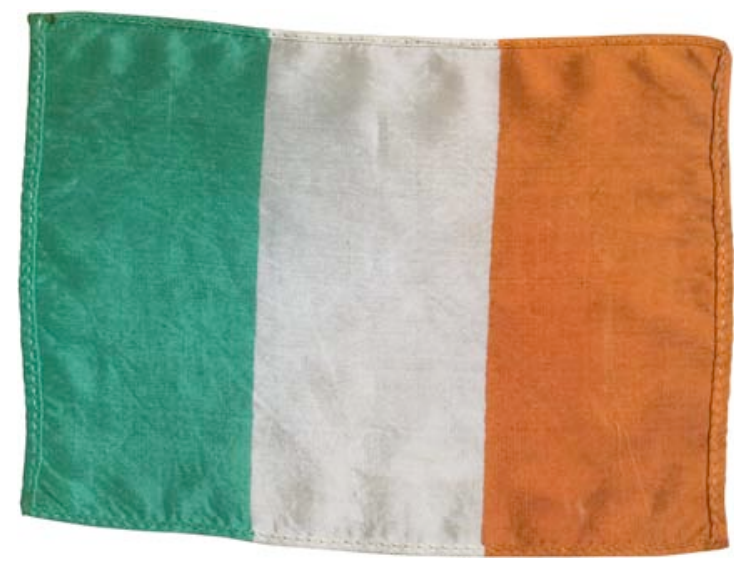

Figure 2. 'The Irish Flag which was carried on board APOLLO 11 1969', photographed at Dunsink Observatory, June 2005 (shown at approximately half the flag's actual size).

My serendipitous discovery in Dublin prompted the idea of constructing a fictional orbit of the moon, an imagined journey to a place still largely inaccessible, partly in reference to Collins' experience and partly to the iconic flag. Using these speculative points of reference, I have been working on a slow, looping, animated film featuring a single orbit around the moon, rendered from a computer model and based on photographic data collected in 1994 by a NASA spacecraft called Clementine. Much of the familiar $16 \mathrm{~mm}$ film footage from the Apollo missions was shot at a low frame rate, which when played back at normal speed has the effect of accelerating the spacecraft's apparent movement above the moon. This is tantamount to speeding up the astronauts' experience and the one's temporal encounter with that experience. In contrast, I wanted to recreate an orbit that occurs in real time, so to speak, where there is a correlation between the physical space covered in a particular period of time and the time spent viewing this unfolding scenario. Very little other than the camera is animated. The vista 
changes almost imperceptibly and the camera's point-of-view slowly rotates over the course of almost two hours. There is occasional cutting between different viewpoints but over the course of the film only a single orbit is completed. One travels slowly and inexorably from full sunlight to the dark side of the moon and back.

The Irish Flag which was carried on board APOLLO 111969 .

Figure 3. Typed label commemorating the flag's journey.

The animation is rendered from a computer model in which the positions and orbits of the earth, moon and their relation to the sun and stars have been plotted to correspond as far as possible to actuality, although as I am not an astronomer, it is a logical model if not a completely accurate one. The surface of the moon itself is based on photographic data collected in an automated and systematised way by the remotely controlled spacecraft, Clementine, originally developed to test space hardware for military purposes by the U.S. Department of Defense (DoD).[7]

Clementine mapped the moon photographically over a period of approximately two months between $26^{\text {th }}$ February to $22^{\text {nd }}$ April 1994, generating 1.8 million photographs at a resolution of 100 metres per pixel. These have since been collated to form a mosaic of the entire surface of the moon. Data collected by the spacecraft also revealed the possible existence of ice in craters around the moon's south pole, an observation confirmed by the subsequent Lunar Prospector mission in 1998. After successfully mapping the entirety of the moon, Clementine was intended to go into orbit around the near-Earth asteroid, 1620 Geographos, but a malfunction occurred causing one the spacecraft's attitude control thrusters to fire constantly for 11 minutes, using up its fuel supply and causing Clementine to spin at $80 \mathrm{rpm}$. No longer a useful spacecraft, in the words of a DoD spokesperson, it orbits the sun once every 11 years.[8]

The lunar surface in the model is created from displacement maps based on fragments of a digital elevation model (DEM) developed by Anthony Cook who has been working with the Clementine data for a number of years. The Clementine mission was not originally intended to map the moon, let alone generate such detailed height data but Cook used a stereo-matching process on the areas of overlap between adjacent photographic 'tiles' in order to extract depth information about the moon's mountains and craters from the two dimensional images.[9] Given that only the overlaps could be analysed, the DEM contains areas of detail alternating with sections where there is a complete absence of information. Despite this, Cook's work offers the highest resolution record of the moon's topography. As my animation is an approximation rather than a scientific representation, I have used his DEM as a basis for digitally editing and painting displacement maps for use with Maya and Renderman, in conjunction with the Clementine source mosaics. As such my representation is intended to have some degree of correlation with the actual moon, though in many respects it is a partial equivalence. Above all, as I will explore later, it is projection from a photograph, a technical representation, into a space of possibility. 

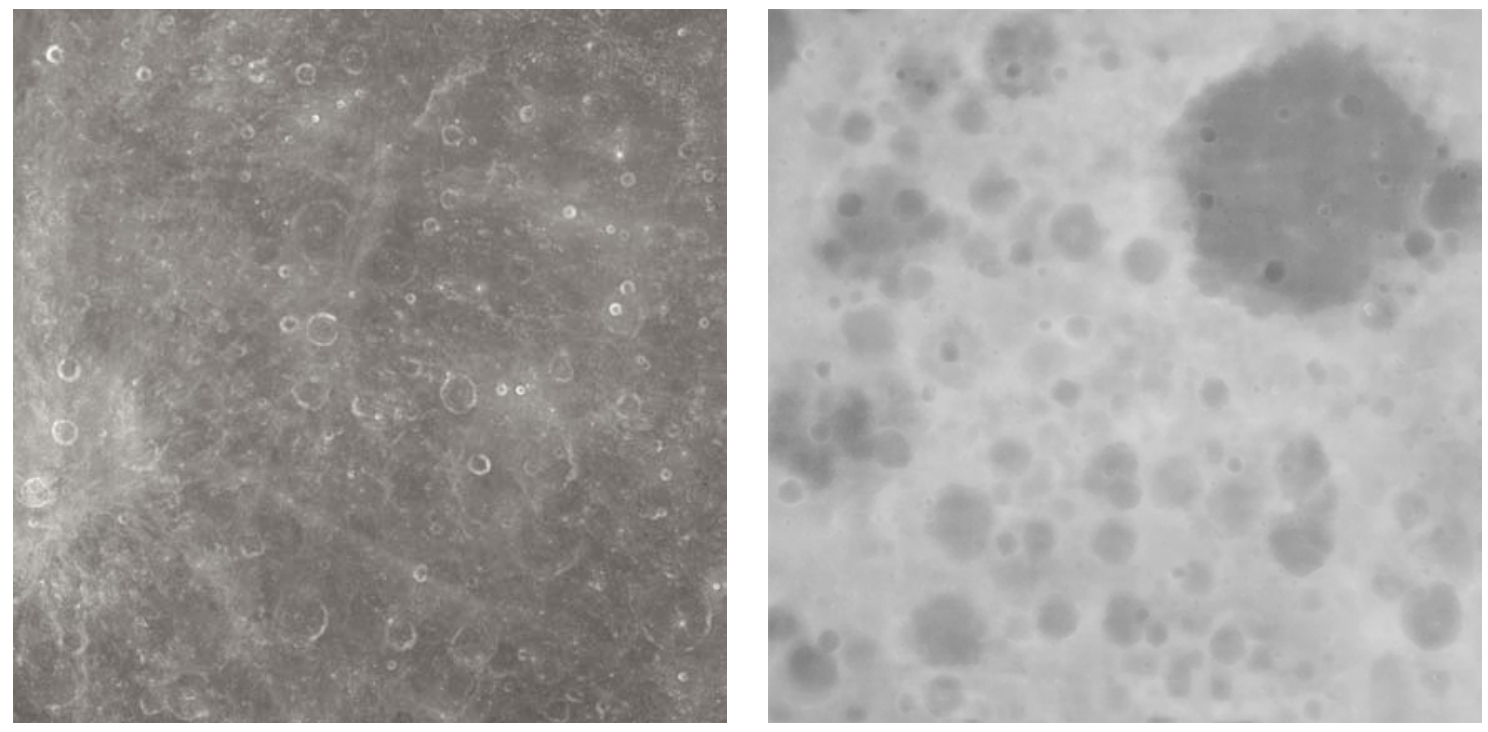

Figure 4. Left: Photograph derived from the Clementine mosaic (USGS $750 \mathrm{~nm}$ basemap).

Right: Displacement map based on A.C. Cook's digital elevation model, itself derived from the Clementine mosaic. The darker the area of the map, the deeper the craters and the lower lying the terrain (and vice versa).

Like many of the projects and technology associated with space exploration, Clementine was originally intended solely for military research, in this instance concerning defence against ballistic missiles. It was a relatively low budget project aimed at testing the capabilities of sensors and spacecraft components under extended exposure to space conditions and was developed under the auspices of the Ballistic Missile Defense Organization (a successor to the Strategic Defense Initiative or 'Star Wars' programme). Almost as an afterthought, it seems, the U.S. Department of Defense was persuaded by NASA to incorporate a lunar mapping dimension to the mission where the moon was used as a readymade target for tracking purposes. Nearly 14 years later, the Clementine dataset remains perhaps the most comprehensive set of lunar observations. With echoes of the song that gave it a name, it will soon be superseded by current or imminent explorations by the Japanese, Chinese, Indian and U.S. space agencies. The inevitable march of scientific and technological progress allied to the development or maintenance of national and international prestige - will lead to an inevitable redundancy of the information previously regarded as cuttingedge. For me, there is an element of melancholy about the obsolescence generated by this ubiquitous drive to innovate.

The idea for the film also emerged in response to thinking about and working with the computer as a means to make artworks, using a variety of software to model and render three dimensional objects and spaces. Without wanting to deal overly in abstractions, when one is immersed in this medium a modelled object occupies a curious realm, hovering somewhere between imagined, projected and tangible states. There is a striking correlation between the model as an idea, a cognitive projection, and its representation on a screen, as a printed image, a rapid prototype, and so on. As an idea and an electronic construction it is embodied in code with the help of whatever interface is to hand. This code is also the means through which the object is made 
manifest. It does not have a necessary causal or indexical relation to the outside world, as is the case with a photograph which is to some degree formed through the properties of light at a particular time and place. It occupies an additional world, a synthetic, parallel space. But such manifestations also have another presence which has as much to do with the internal machinations of one's brain as with their status as images, electronic or otherwise.

'One can follow this sequence of images, just as if the imagination had become selfsufficient; or as if it had travelled from inside (let's say from the cranium) to outside (into the computer); or as if one could observe one's own dreams from the outside.'

Vilém Flusser [10]

Although this is primarily an opportunity to discuss a work-in-progress, I want to reflect briefly on some related ideas, in particular, Vilém Flusser's thoughts on media and representation. Unorthodox in approach, his work sits on the margins of established discourses and is characterised by its breadth, its 'mental leaps between disciplines' and its explorations of a magical consciousness in relation to the foundations of modern science.[11] Despite this unorthodoxy (or perhaps because of it), he offers a refreshing, polemical and idiosyncratic philosophy of media that is useful when pondering and working with this technological space.

Writing in the 1980s, Flusser intriguingly discusses a 'new imagination' with respect to technological media, exploring the relationship between the world and its representations through image, text, scientific notation and latterly what he called technical or calculated images. In Flusser's thinking, when imagining something, we step back from the world 'into ourselves' in order to comprehend better the context we are in.[12] Pictures are a means of fixing the products of imagination, making them communicable and accessible to others. But they also operate as two dimensional surfaces across which the eye wanders as it pleases. Rather than offering a conclusion, pictures present a wholeness and in this sense, for Flusser, they are magical. They present states of things and allow for contradictory interpretations. If we step back from the world into ourselves in order to see the context we are in, we lose the specific nature of the thing. It becomes hidden by the image.

Throughout his work, Flusser argues that this predisposition to imagine, to think in images, and to relate to the world through images was characteristic of a symbolic, magical consciousness radically altered through the invention of writing. In order to determine the image's meaning and better direct interpretation, linear writing began to supplant the image and in doing so the synchronous, magical consciousness Flusser associates with it was gradually replaced with a new historical logic. But writing was developed to demystify the image and it, too, obscures the image embedded within it, further distancing one from the lebenswelt, the world that is lived.

To continue with his train of thought, the linearity of written language was perhaps too uncritical when applied to the rationalising functions of an emerging scientific approach. Therefore the bits or 'pixels' that constituted writing (that were torn from the image) had to be processed formally; they had to be calculated. The numeric code remained tangled in the alphabetic code until calculus was developed and refined and Flusser saw such calculation as the highest expression of a historical consciousness. 'Only an imagination that has been thoroughly calculated can be considered explained.'[13] Mathematical notation provided a means of determining the nature of 
the world with less ambiguity, but following Flusser's logic, in time these scientific 'texts' become abstract to such a degree that their connection to the lived world becomes increasingly tenuous.

As a result, Flusser determines that 'technical images', the first instance of which was the photograph, were developed in order to illuminate the abstractions embodied by such texts.[14] His critique of photography is based on his configuration of the shift from magical/ symbolic thought through historical/ linear thought, a thinking and consciousness effected through writing, to a new image-based consciousness reliant on scientific, calculated thought. The photograph owes its existence to such thinking but, true to its status as an image, that is, as a surface showing states of things, it acts as a transparent window onto the world. For Flusser this is a key moment in the development of consciousness. It signals a shift from a linear to an image code once again but this 'new' imagination is different from the one superseded by linear thought. The photograph freezes events into scenes, it effects the 'damming up of history'. It signals the end of the dominance of linear, historical thinking. The photograph may appear to reflect the world directly as it has an indexical relation to the scene it pictures and the light or likeness it captures. But on the contrary, the vector of signification has reversed. For Ströhl, 'photographs are post-historical because they do not find their origin in a process of abstraction, but go through a process of concretisation.' [15] In this sense Flusser saw digital images of all kinds as successors to the photograph. They are projections.

At the dawn of the Enlightenment project, Descartes developed a methodical system - a rationality based on doubt - that contributed to the establishment of the modern scientific approach. The success of this approach is evidenced all around us. Thought as expressed via language - language in Flusser's broad sense, from text to mathematical calculation - is like a net cast out into the distance. The lines of the net correspond to language and the density of the net's weave corresponds to the measure we have of the world. Its intersections, knots and nodes coincide with what is habitually referred to as real or actual. The ineffable, in contrast, is that which escapes language, that which slips through the net and to sense the world's ineffability is both necessary and perhaps inescapable.[16] There is a point at which languages do not suffice.

But as the net's density and our objective comprehension of the world increases, the more this language intercedes and the more alienated we become. In this sense the world is constructed through language and the limits of language are the limits of the world. For Flusser, the increasing density and precision of the net obscures the world and ultimately leads to an impasse. He regards this crisis as the end of history, in his terms, the end of the historical consciousness brought into being though linear writing.[17] The gap between humans and the world is most significantly demonstrated in physics where the net is unfathomably dense. Yet the digital computer - a representing machine like no other - is one consequence of such calculatory abstractions. For this reason it is pivotal in the configuration of our relationship to the world. The question is, how is it possible to remain critical in relation to it when so many areas of life are saturated with computation?

Mediated, calculated, technical images surround us and jostle with the world for our attention. At some point it becomes necessary to project, to take what is inside and externalise it, to reverse the vector of signification. Such a concretising gesture, as Flusser called it, has an affinity with the desire or motivation to create space for something, be it an imaginative process, a train of thought, play or speculation; space 
for imagining possibilities rather than mapping probabilities, for seeing the possibility of difference. If language is like a net cast over the world, the language and methods of science are becoming ever more precise, the net ever finer. The ineffable, what we sense to be beyond such articulation, persists despite the precision of description. I wonder if the 'description' is all that can be admitted. From a description, a photograph for example, the thing can be reconstructed but perhaps its significance could be measured in terms of its resonances rather than its accuracy. Imagined or perceived possibilities are produced in response to the objective world, the world that outlasts us (and which may or may not absorb these possibilities, of course).

'Formalizability and computation on the one side, and intuition and imagination on the other, are two poles of the "mixtum compositum" [of] media art with regard to the actions of the subject. To understand these poles as two ends of a scale that can be played in both directions in an alternative to a dualistic view, which is an easy option but also fatal, if one remains trapped within this way of thinking.'

Siegfried Zielinski [18]

\section{ACKNOWLEDGEMENTS}

Thanks to Professor Evert Meurs and Colin Melody, Dunsink Observatory; Kevin Atherton and Leah Hilliard, National College of Art \& Design, Dublin; Dr Anthony Cook, Aberystwyth University; Scott Eaton; Dominic Davenport, Escape Studios, London; Trent Hare, USGS, Flagstaff; Paul Bourke, University of Western Australia, Crawley; Marcel Marburger, Flusser Archive/ Universität der Künste, Berlin. This work forms part of a fellowship supported by the AHRC.

\section{References}

[1] 'Michael Collins was the first Irishman in space, he remained in lunar orbit while his Apollo 11 colleagues, Edwin Aldrin and Neil Armstrong walked on the moon (21st July 1969).'

This is the 46th entry from a list of observations about Ireland entitled 'Did you know?' to be found on the website of the Department of the Taoiseach.

http://www.taoiseach.gov.ie/index.asp?locID=197\&docID=209

[accessed 30.05.08]. The son of a Major General in the United States Army, Collins' was born in Rome, Italy on 31st October 1930.

[2] MICHEL, J: Dora. London: Weidenfeld and Nicolson, 1979. A harrowing and moving account of Michel's internment at Mittelbau-Dora, the Nazi concentration camp and underground factory where slave-labourers were forced to build the V-2 rockets that were direct precursors to the U.S. and Soviet space programmes. DEGROOT, G: Dark Side of the Moon: The Magnificent Madness of the American Lunar Quest. London: Jonathan Cape, 2007. DeGroot's caustic analysis minutely explores the political and economic motivations behind the race to the moon. Also, BRZEZINSKI, M: Red Moon Rising: Sputnik and the Rivalries that ignited the Space Race. London: Bloomsbury, 2007.

[3] For example, LUCIAN of Samasota: True History (2nd century A.D.); GODWIN, F: The Man in the Moone (1638); de BERGERAC, C: Journey to 
the Moon also known as The Other World: the Societies and Governments of the Moon (1657).

[4] For example, CHAIKIN, A: A Man on the Moon: The Voyages of the Apollo Astronauts. Harmondsworth: Penguin, 1995.

[5] Strictly speaking, Apollo 10 command module pilot, John Young, was the first to experience such isolation in his spacecraft while the other two members of the flight crew in the lunar module, Eugene Cernan and Thomas Stafford, descended to 50,000 feet above the moon's surface before re-docking with the command module.

[6] COLLINS, M: Carrying the Fire: An Astronaut's Journeys. New York: Cooper Square Press, 2001, p402-3.

[7] The online archive of the United States Geological Survey has the most up-todate set of Clementine data:

http://webgis.wr.usgs.gov/download/Clementine_UVVIS_ULCN2005_Warp/

For information on Clementine see:

http://astrogeology.usgs.gov/Projects/Clementine/;

http://nssdc.gsfc.nasa.gov/planetary/clementine.html;

http://www.nap.edu/html/ssb_html/Clementine/clemmenu.shtml;

http://www.defenselink.mil/photos/newsphoto.aspx?newsphotoid=520

[all accessed 30.05.08].

An associated sound work references the Clementine spacecraft itself. This was apparently named after the doomed heroine of the American folk song, 'Oh! My Darling, Clementine' as it would be 'lost and gone forever' after the mission was over. The sound work features the original song stretched and slowed to the duration of the lunar orbit featured in the film, resulting in a generative sonic space in which the animation - and one's thought processes can unfold.

[8] Transcript from a U.S. Department of Defense News Briefing 3rd December 1996: http://www.defenselink.mil/transcripts/transcript.aspx?transcriptid=731 [accessed 30.05.08]

[9] COOK, A.C: http://users.aber.ac.uk/atc/dems.html [accessed 30.05.08].

[10] FLUSSER, V: A New Imagination. Writings, (ed. Ströhl, A), Minneapolis and London: University of Minneapolis Press, 2002, pp110-116, p114.

Such a concretising gesture '... neither abstracts, nor steps backwards; just the opposite, it concretises, it projects. Certainly, both gestures lead to the creation of images (and both can be therefore called imagination) but then one is really dealing with different sorts of images. The images created by the traditional imagination are two-dimensional because they have been abstracted from a four-dimensional life world. In comparison, the images of the new imagination are two-dimensional, because they have been projected from zerodimensional calculations. The first type images signify the life- world; the second type represents calculations. The vectors of meaning of both types of imagination point in opposite directions, so that the first type must be interpreted differently than the second type. This is the real reason why traditional image criticism misinterprets the new images.' p114.

[11] ZIELINSKI, S: Deep Time of the Media: Towards an Archaeology of Hearing and Seeing by Technical Means. (Trans. Custance, G), Cambridge, Mss. and London: MIT Press, 2006, p97. 
[12] FLUSSER, V: A New Imagination. At the online Flusser seminar hosted by Medcad / the vilém_flusser_archiv, http://217.76.144.67/unesco/intro/index.html [accessed 15.03.05]. This is a different version of the text included in Writings [6].

[13] see FLUSSER, V: Thought and Reflection (1963). Flusser Studies Online Journal, Issue 01, November 2005. http://www.flusserstudies.net [accessed 30.11.05]; see also, A New Imagination. Writings, p112.

[14] FLUSSER, V: Towards a Philosophy of Photography. (Introduction, Von Amelunxen, H; trans. Mathews, A), London: Reaktion, 2000 (1983).

[15] STRÖHL, A: Introduction to FLUSSER, V: Writings, p.xxv.

[16] see WITTGENSTEIN, L: Tractatus Logico-Philosophicus. (Trans. Pears, D.F. \& McGuiness, B.F.) London: Routledge, 1992 (1921), p74. The sole proposition of the final, seventh set of the Tractatus: 'What we cannot speak about we must pass over in silence'.

[17] This is reminiscent of Borges' story of the tattered remains of an infamous map that was the same scale as the empire it represented, a relic of overdetermination. BORGES, J-L: Of Exactitude in Science. A Universal History of Infamy, Harmondsworth: Penguin 1984, p131.

[18] ZIELINSKI, S. op.cit. p277. 